\title{
Early Nursing Reform in Nineteenth-Century London: A Doctor-Driven Phenomenon
}

\author{
CAROL HELMSTADTER*
}

\section{Introduction}

Florence Nightingale's status as a national heroine, her charisma and her excellent sense of public relations led to the popular belief that she and her lady nurses in the Crimea, and later, her school at St Thomas's, miraculously transformed nursing almost overnight. Aside from the fact that this is hardly the way historical processes work, and despite the very convincing studies of revisionists such as Monica Baly and Christopher Maggs, this interpretation has shown remarkable persistence. ${ }^{1}$ From a twenty-first century perspective it is obvious that nineteenth-century nursing reforms were complex and multiform, reflecting many of the major trends of their time such as the efforts of women to break into the public sphere, the rising standard of living, the religious revival with its emphasis on good works and its violent denominational controversies, the reformation of manners, and, most important, the rapid development of clinical medicine. In this article I shall argue that the very important contributions of Nightingale and the new lady nurses have overshadowed the significant reforms which doctors in the twelve London teaching hospitals made in the earlier part of the nineteenth century.

Indeed, it was the new "scientific" doctors, as they called themselves, in the teaching hospitals who created the demand for better nursing. ${ }^{2}$ The new medicine in London developed in the voluntary hospitals in the first part of the nineteenth century. Based on clinico-pathological correlation, localism and hospital-based statistics, pioneered in large part by the Paris school of medicine, it was to make these hospitals the centre of medical education and prestige. More important than these

* Carol Helmstadter, BA, BScN, MA,

Government Relations Officer (retired), Ontario Nurses' Association, 34 Chestnut Park, Toronto M4W 1W6, Canada.

A shorter version of this article was presented at the Canadian Society for the History of Medicine meeting in Edmonton in May 2000. I thank the Wellcome Trust for a travel grant and the Hannah Institute for the History of Medicine for funding which enabled me to do the research for this article.

${ }^{1}$ Baly has written two articles specifically to debunk this traditional view, 'The Nightingale nurses: the myth and the reality', in Christopher Maggs (ed.), Nursing history: the state of the art, London, Croom Helm, 1983, pp. 33-59, and 'Florence Nightingale and the establishment of the first School at St. Thomas's: myth v. reality', in Vern Bullough, Bonnie Bullough and Marietta P Stanton (eds), Florence Nightingale and her era: a collection of new scholarship, New York, Garland, 1990, pp. 3-22.

${ }^{2}$ Brian Abel-Smith, The hospitals 1800-1948: a study in social administration in England and Wales, London, Heinemann, 1964, pp. 16-31, 43-4, 66. 


\section{Carol Helmstadter}

characteristics from a nursing perspective, however, was the shift in therapeutics which the new medicine brought. After making a comprehensive study of British hospitals in the early 1860s, Dr J S Bristowe of St Thomas's and Mr Timothy Holmes of St George's Hospitals found the changes in the treatment of many forms of disease, and especially fevers and other acute illnesses, truly remarkable. A nourishing and stimulating plan of treatment was gradually replacing the old lowering therapies. "Depletion in the exaggerated form in which it formerly prevailed, has ceased to be the rule of practice in every hospital or infirmary which we visited", Bristowe and Holmes wrote in 1863, "and the employment of stimulants and nourishment in the treatment of acute affections has become everywhere habitual."

As well, a clean technique in the local treatment of wounds was coming in. Tow, cotton wool or lint which had to be destroyed after one application were replacing sponges, and where sponges were in use, they were usually used for one patient only, and later destroyed or chemically purified. ${ }^{3}$ Disposable dressings were more costly and far more time consuming than the old routine of the surgeon going down the ward from patient to patient with one sponge and one basin of water. The new practice placed a heavier burden on the nurses who were responsible for making and washing the dressings. The liberal diets and the greater use of stimulants were much more expensive than the old low diets and required twenty-four hour aroundthe-clock nursing care for, in the days before intravenous fluids, food and drink were frequently ordered every half hour. And doctors had always expected to be informed of any changes for the worse in the patient's status. ${ }^{4}$ Such attendance required responsible and alert nurses as well as more numerous nursing staff, which was also very costly. For much of the century, in the absence of such nurses, the teaching hospitals were forced to rely on medical students for the nursing care of acute cases. ${ }^{5}$

By the mid-nineteenth century there were twelve teaching hospitals in London. St Bartholomew's and St Thomas's were medieval foundations, the Westminster, St George's, Guy's, the London and Middlesex Hospitals were established in the eighteenth century, and the Royal Free, University College, Charing Cross, King's College and St Mary's Hospitals were founded in the nineteenth century. By the end of the century, each of these hospitals had its own medical school and its own nurses' training school. These hospitals were all voluntary or charitable institutions, wholly dependent on their endowments, subscriptions or donations for their incomes, a fact which was to have a profound effect on the development of the new nursing. St Bartholomew's, St Thomas's and Guy's, often referred to as "the endowed hospitals", were wealthy but the remaining nine frequently had, and some always had, severe difficulties raising adequate funds to support their work. By the end of the century,

\footnotetext{
${ }^{3}$ Parliamentary Papers (hereafter PP), Sixth Report of the Medical Officer of the Privy Council 1863, 1864, vol. 28, pp. 463-743, on pp. 484-5.

${ }^{4}$ Charing Cross Hospital Archive (hereafter $\mathrm{CCH}$ ), Minutes of Board of Governors 1834-45, pp. 78-9; St Thomas's Hospital Archive, London
}

\author{
Metropolitan Archives/H1/ST (henceforth STH), \\ 'Hints for nurses', pp. 1-4, SJ/A39/7. \\ ${ }^{5}$ See, for example, John Flint South, Facts \\ relating to hospital nurses, London, Richardson \\ Bros, 1857, pp. 10-12; Robert Bentley Todd, \\ Clinical lectures on certain acute diseases, \\ Philadelphia, Churchill, 1860, p. 133.
}




\section{Early Nursing Reform in Nineteenth-Century London}

even Guy's and St Thomas's were working with deficit budgets. Under these circumstances it was difficult for nursing to compete for the hospitals' limited funding against the medical schools, medical research and the more expensive supportive therapeutics.

Each of the twelve hospitals had its unique constitution, traditions and culture, but, at the beginning of the nineteenth century, all shared the common problem of unsatisfactory nursing services. Administrators in these hospitals regularly consulted each other about their nursing difficulties, and, because each tried to learn from its peers, the history of nursing reform at one hospital generally reflects the course of nursing reform in London during the century. In this article, although referring to the other teaching hospitals, I will focus primarily on the Westminster Hospital to illustrate the doctors' role in the gradual development of the new nursing from the end of the Napoleonic Wars until 1880, the date generally given for the birth of the modern trained nurse.

While physicians and surgeons did not sit on the Board of Governors at St Thomas's, St Bartholomew's, the London or Guy's, doctors played an active role in founding and running the other eight hospitals, and were usually very outspoken members of their boards. ${ }^{6}$ At the Westminster, the Weekly Board, or House Committee as it was later called, ran the hospital on a day-to-day basis. It included a number of lay governors plus all the hospital's physicians and surgeons. ${ }^{7}$ Throughout the century these physicians and surgeons pressed hard for a better nursing service. It is no coincidence that the last three hospitals to introduce nurses' training schools, Guy's, Bart's and the London, were institutions which disbarred doctors from their boards. The fourth hospital, St Thomas's, where the Nightingale school was established in 1860, was a bit of an anomaly. The Nightingale Fund contract paid the old matron, Mrs Wardroper, who was not a nurse, the apothecary, Mr Whitfield, and some of the old sisters to train the probationers. Florence Nightingale thought the hospital used the probationers as full-time assistant nurses rather than as pupils. In the 1860 s and early 1870 s she and Henry Bonham-Carter, the Secretary of the Nightingale Fund, tried on several occasions to move the school from St Thomas's to a different hospital where they could start again. ${ }^{8}$ The Nightingale school was to

\footnotetext{
${ }^{6}$ While doctors were very active in the founding of the London Hospital, due to a squabble between the physicians and surgeons in the eighteenth century, officers on staff were disbarred from serving on the Board. (A E ClarkKennedy, The London: a study in the voluntary hospital system, 2 vols, London, Pitman Medical Publishing Co., 1963, vol. 1, pp. 85-7.)

${ }^{7}$ Westminster Hospital Archive (hereafter WH), London Metropolitan Archives/H2/WH, Minutes of Board of Governors (hereafter MBG), 26 June 1816, A1/25.

${ }^{8}$ Baly, 'The Nightingale nurses', op. cit., note 1 above, pp. 39-40. "What we call the Nightingale system was a hotch potch of what the Fund could wring out of St. Thomas'swhich was not much", Baly writes. "What the nurse was taught and who taught her and who
}

\begin{abstract}
examined her are questions which were left unanswered" ('The First School at St. Thomas's', op. cit., note 1 above, pp. 12, 20). Although it was founded in 1860 , Nightingale felt her school did not provide the moral and practical instruction which she wanted until 1872 when Miss Torrance, followed by Miss Machin, became the Home Sisters. They were not allowed to give clinical instruction in the wards. Baly indicates that Nightingale chose St Thomas's for her school because she hoped to see it rebuilt as a model hospital. Bonham-Carter thought Wardroper incapable of making a sound judgement and Nightingale thought she governed like a virago. (Monica E Baly, Florence Nightingale and the nursing legacy, 2nd ed., London, Whurr, 1997, pp. 31-6, 140, 148-54.)
\end{abstract}




\section{Carol Helmstadter}

be the last to introduce a trained nurse as matron in 1887 when Mrs Wardroper retired.

\section{A Want of System and Regularity: Nursing at the Beginning of the Century}

Nursing services in 1815 were very different from those of today. The matron was not a nurse but rather a housekeeper whose duty it was to see that the wards were clean and in good order and the kitchen staff and nurses in attendance and behaving properly. The medical staff, not the matron, were responsible for the nursing care of the patients. ${ }^{9}$ The nurses on whom these leading edge doctors had to depend were primarily cleaning women. They received no training whatsoever in nursing but they did give the patients some help, while those patients who were able assisted the nurses with both their cleaning and nursing duties. Most nurses worked sixteenhour shifts ${ }^{10}$ and had almost no paid time off. If they were ill or were granted a leave of absence, they had to find and pay their substitutes themselves. ${ }^{11}$

Following the Napoleonic Wars, the Weekly Board at the Westminster found their 78-year-old matron, Mrs Morterras, guilty of many instances of gross neglect. Matters came to a head when, in April 1818, the House Surgeon complained that Night Nurse Thomason was drunk the preceding night and had not given a patient his medicines. She said that she had, but the patient said she had not. Nurse Thomason was immediately let go and the following month the Board forced Mrs Morterras to resign. ${ }^{12}$ The new matron, Mrs Ann Cox, discharged a number of nurses and saw that the wards were clean and the patients comfortable. ${ }^{13}$ However, when in 1826 a Committee of Enquiry was struck to investigate a porter who had been embezzling beer, the Committee found there was "a total want of system and regularity in almost every department of the establishment". The most immediate concern in the matron's department was the way the nurses often failed to follow the doctors' orders and went out of the hospital without notifying the matron, leaving their wards unattended. The Board reinforced its regulation that patients, nurses and servants were never to leave the hospital without written permission. ${ }^{14}$ It is indicative of the governors' view of the nurses that they were lumped in with the patients and other servants of the hospital.

The nursing problems at the Westminster were standard throughout all the hospitals, and, generally speaking, doctors and administrators tried to deal with them by raising the nurses' pay and tightening regulations. At the London Hospital, Sir William Blizard, twice president of the Royal College of Surgeons and founder of the hospital's medical school, came as a guest to a House Committee meeting on

\footnotetext{
${ }^{9}$ Benjamin Golding, Historical account of the origin and progress of St. Thomas's Hospital, Southwark, London, Longman, Hurst, Rees, Orme and Brown, 1819, pp. 189-215; Abel-Smith, op. cit., note 2 above, pp. 7-8.

${ }^{10} \mathrm{WH}$, Laws and Regulations for the Government of the Westminster Hospital 1835, pp. 9-10, 31-2, A34/1/1.
}

\footnotetext{
${ }^{11} \mathrm{WH}, \mathrm{MBG}, 10$ Sept. 1850, A1/36; 12 Apr. 1850, A1/38; 1 July 1862, A1/40.

${ }^{12}$ WH, MBG, 22 Apr., 13 and 27 May 1818, A $1 / 25$.

${ }^{13}$ WH, MBG, 28 Oct. 1818, 6 Jan. 1819, 19 Jan. and 27 Oct. 1819, H2/WH/A1/25; 8 Aug. 1821,16 July $1822, \mathrm{~A} 1 / 26$.

${ }^{14} \mathrm{WH}, \mathrm{MBG}, 13$ and 20 Dec. 1826, A1/27.
} 


\section{Early Nursing Reform in Nineteenth-Century London}

19 December 1818. He was accompanied by Drs Buxton and Robertson. The topic of discussion was the need to improve the nursing service. The doctors wanted a more respectable class of women who would stay for longer periods and who would not go in and out of the house without permission. This hospital was the exception to the rule in thinking that the nursing problems lay not in the regulations but in the matron's failure to enforce them. She was really unequal to her duties and needed the power to suspend uncooperative nurses and servants. She should not allow the nurses to do their washing in the wards and the nurses should wear uniforms. The Committee allotted $£ 50$ for gratuities to those nurses who exhibited good conduct and who had been in service for a year. ${ }^{15}$

In the 1830s, St George's was experiencing the same problems but it had found a matron who was prepared to enforce the rules. The hospital had made the nursing regulations stricter in 1836 and again in 1837, but to no avail. In July 1839 at a meeting of the Weekly Board attended by a large number of the medical staff, Dr Seymour moved, seconded by Sir Benjamin Brodie, one of the two or three most eminent London surgeons, that a committee be formed to enquire into the causes of the nursing problems. ${ }^{16}$ It was absolutely necessary to have an efficient staff of nurses, for the nursing was vitally important to the welfare of the patients. The assistant and night nurses did not have sufficient knowledge for their position, and their rapid turnover in many cases posed a real danger to the patients. As at the London, the Board decided to pay the nurses a little more. They also recognized the need for clinical experience: the head nurses were to be drawn only from experienced and qualified assistant and night nurses. In addition, the hospital should give more consideration to the nurses' comfort.

The stricter regulations which had been introduced in 1835 when the matron, Miss Steele was hired, and which she had enforced "without discretion of temper", caused considerable ill feeling among her staff. ${ }^{17}$ In 1840 Steele's zealous application of the hospital rules was to lead to her undoing. She did not always "preserve that command of temper and language which is so necessary in the government of a large establishment". Without such manners it was not possible to inspire those in her department with "the kindly feeling and mutual good will which might be expected to actuate all those who are engaged in a common work of pure Christian benevolence". Steele felt forced to resign because, she said, she could not work in harmony with the medical officers. ${ }^{18}$

In 1834 the Westminster moved to a new purpose-built hospital in the Broad Sanctuary and rewrote the nursing regulations in a stricter and more detailed form. What was included suggests, as is frequently the case with hospital rules, what was not being done. The matron must see that the night and day nurses were in their wards at the breakfast and dinner hours, and should visit the wards to be sure that the medicines were properly administered. The nurses had to be able to read handwriting and were to prove themselves honest, sober and kind. Their nursing

\footnotetext{
${ }^{15}$ London Hospital Archive (hereafter LH), Minutes of House Committee, 19 Dec. 1818, A5/6.

${ }^{16} \mathrm{St}$ George's Hospital Archive (hereafter SGH), MBG 1838-42, 31 July 1839.
}

\footnotetext{
${ }^{17}$ Ibid., 7 Aug. 1839

${ }^{18}$ Ibid., 16 and 23 Dec. 1840.
} 


\section{Carol Helmstadter}

duties consisted of carrying out the orders of the doctors, seeing that the patients took their medicine, and watching the patients, especially at night, so that they could report their symptoms to the medical officers at their next visit, or, in the case of emergency, summon the Apothecary or House Surgeon. They were to assist those patients who were unable to wash themselves, and finally they were to prevent the patients and their visitors from bringing in or taking out provisions and liquor, and maintain quiet and good order in the wards. The nurses themselves were not to take any provisions from the hospital and were not to accept any money or gifts from the patients. In addition to all this, they had to clean the whole hospital. ${ }^{19}$

Despite the clearly spelled out new regulations, Mrs Cox continued to have the same problems with the nurses as formerly. In August 1836, the matron reported that night nurses Jones and Early slept during the night. The Secretary investigated and discharged Early because she had been drunk more than once, as well as sleeping on duty. Jones, on the other hand, was a good nurse who did not drink but only slept during the night, so she was kept on after being reprimanded. ${ }^{20}$ In the same month, the House Surgeon found the night nurse in Northumberland Ward asleep several times, while Evans, the day nurse, had accepted a gift of meat from a patient. Macklin, the night nurse in Bouverie Ward, did not call the Apothecary for an alarmingly ill patient until after he was dead. The nurses were warned they would be discharged if they repeated these offences, but Macklin, nevertheless, only a month later accepted money from the wife of a patient and also used abusive language to another patient. ${ }^{21}$

In February 1838, Elizabeth Robinson, the night nurse in the men's surgical ward, got very drunk and caused a disturbance, borrowed money from one of the patients and went out of the hospital without permission, a not unusual incident. But these incidents were so frequent that the governors appointed a committee to find out why so many of their nurses were such disasters and why the turnover was so high. ${ }^{22}$ The committee, which included Dr Rose and the assistant surgeon, Mr F Hale Thomson, met several times and also made personal visits to other hospitals to examine their nursing practice. They concluded that the causes of the poor nursing at the Westminster were the low wages, and the fact that the night nurses formed a separate team which did not co-operate with the day nurses.

It was decided to hire five women of a superior class, who would be better paid, and would be called sisters. ${ }^{23}$ Mrs Savery, the matron at St Thomas's had pioneered this system of supervision. She felt the position of head nurse, or sister as the position was called at St Thomas's, involved so much responsibility that it required a person from a higher social class. She therefore hired women from the class of shopkeepers or head servants to be sisters rather than promoting the working-class nurses as in the past. ${ }^{24}$ At the Westminster, each sister was to supervise several wards, keeping

\footnotetext{
${ }^{19} \mathrm{WH}$, Laws and Regulations of the Westminster Hospital 1835, pp. 9-10, 26-8, 31-2, A34/1/1.

${ }^{20}$ WH, MBG, 9 and 16 Aug. 1836, A1/31. 31 .
}

\footnotetext{
${ }^{22}$ WH, MBG, 27 Feb. 1838, A1/31.

${ }^{23}$ WH, MBG, 3 Apr. 1838, A $1 / 31$.

${ }^{24}$ Guy's Hospital Archive (hereafter GY), London Metropolitan Archives/H9/GY, Report of the Charity Commissioners, June 30 1837, pp. 54-60, A71/1.
} 


\section{Early Nursing Reform in Nineteenth-Century London}

good order and seeing that the patients received proper nursing care at night as well as in the day. There were then seventeen nurses on staff and the Committee feared that with the possible exception of one or two, none were qualified to be sisters.

No sooner had the Westminster Board fixed upon the new system of nursing than Mrs Cox asked for a raise. She pointed out that when she came in 1818 there were less than 100 patients and only eight nurses and two female servants. In 1838 there were 170 patients, seventeen nurses and four female servants, all of which greatly increased her duties. ${ }^{25}$ Mrs Cox's increasing workload was not unusual. In the 1830s and 1840s the teaching hospitals were having to turn away patients for lack of space. Most expanded their bed capacities and, as a result, they were forced to enlarge their staffs. Not only did the larger number of patients make the matron's housekeeping duties more onerous, but it became almost impossible to run the hospital efficiently with a larger, essentially untrained nursing staff, many of whom stayed only short periods.

It was not easy to find what the governors called superior persons who were willing to work in a hospital. In December of 1838, the Assistant Surgeon reported that Sister Ann Smith was guilty of several instances of incompetency and gross neglect and she was let go. ${ }^{26}$ In February 1841, Henry Hoare, one of the men's surgical wards, was in a state of riot and confusion with the sister completely unable to maintain order among her patients. When House Visitor John Bicknell tried to uncover the cause of the riot, one boy told him it was not his business to explain the cause, while another just smiled when Bicknell threatened to report him to the Board. The sister said the disturbance had arisen over a few potatoes which the matron had sent up for dinner. ${ }^{27}$

Friends of the nurses and patients were smuggling liquor into the wards all the time. In March 1841, the House Visitor reported that the patients in St Matthew and St Mark's wards were extremely insubordinate. The House Surgeon said the sister and her night and day nurses did not give good patient care, while the matron said they did not keep the ward clean. The patients were disorderly-they smoked, drank and played cards, all of which were against hospital rules. And they took improper liberties with the nurses, although from the governors' conversation with the women it appeared that they were as much to blame as the patients. In fact, the sister had one or more patients sitting in her room taking their meals with her, and she allowed them to practice what the governors termed "the grossest indecencies" on herself. ${ }^{28}$

In August of 1842, Jane Dawson, the Sister of Percy and Queen Anne, women's accident wards, was discharged for riotous and disorderly behaviour and for refusing to obey the orders of the matron, as well as threatening to be the death of Anne Waldron, one of her nurses..$^{29}$ However, it was so difficult to find clinically experienced sisters that hospital boards were forced to overlook even more serious failings. For example, in October 1847, Maria Dewar, the night nurse in Queen Anne, was fired

\footnotetext{
${ }^{25}$ WH, MBG, 3 Apr. and 29 May 1838, A1/ 31.

${ }^{26} \mathrm{WH}, \mathrm{MBG}, 11$ Dec. $1838, \mathrm{A1} / 32$.
} 


\section{Carol Helmstadter}

for riotous conduct, drunkenness and assaulting one of her patients. Dewar responded by explaining that if the patients in her ward wished to receive kind and proper nursing care they had to give the sister, Mary Vesey, presents of clothing and gin. Vesey denied accepting presents from her patients. She said she had paid for the bottles of gin and the caps, collar and bits of lace which the patients' relatives brought her. She was reprimanded but kept on. ${ }^{30}$ However, a little over a year later, in January 1849, she was discharged when a patient complained of her harshness and unkindness and two of the surgeons did not support her. Even then, two governors urged that she be reprimanded rather than fired. ${ }^{31}$

Maria Dewar's career illustrates how easily an experienced nurse could move from one hospital to another despite a poor work record. She had been a sister at St George's Hospital where she was dismissed in 1842 for similar reasons-intoxication, disgraceful behaviour in her wards, rudeness to the Chaplain and House Surgeon and leaving the hospital without permission despite the matron impressing upon her the impropriety of so doing while drunk. ${ }^{32}$ Dewar then secured a job as a head nurse at University College Hospital where, in March 1845, she and her night nurse were threatened with discharge because they accepted money from patients. A few months later, in October 1845, Dewar was fired for drunkenness. ${ }^{33}$ Her position as a night nurse at the Westminster was a marked step down from that of head nurse, but she was nevertheless able to find another job.

The nurses were by no means the only members of the hospital staff who were disorderly. For example, on 10 May 1826, Mr Bond, the Apothecary, reported that "the young gentlemen" in the house had been guilty of misconduct two days previously. Mr Casey, the House Surgeon, had entertained his friends until a late hour and the evening had ended in drunkenness and a riot. $\mathrm{Mr}$ Bond made two attempts "by kind remonstrance" to get them to leave the hospital but on the second attempt, Mr Casey seized him by the throat and threatened to murder him. Fortunately Mr Bond was able to get away and summon help to remove Casey and his friends from the hospital. Mr Casey was still ill in bed two days later, so the Board had to wait until the following week to reprimand him. ${ }^{34}$

The first part of the century was an age of riots ${ }^{35}$ and sometimes it was friends of the patients who caused them. As late as 1864, a drunken Irish woman who had been badly burned was brought to the hospital by what was described as a mob of nearly 200 Irishmen and women. The night porter admitted the burn case and managed to shut the door before all but three of the mob could get in. Shortly afterwards another accident case presented. This time the surgery man, who was drunk, opened the door and a large number of the mob surrounding the hospital forced their way in. When the hospital servants tried to expel the riotous persons they attacked them with the surgery's tongs, poker and benches. They injured the

\footnotetext{
${ }^{30} \mathrm{WH}, \mathrm{MBG}, 19$ Oct. 1847, HA1/35.

${ }^{31}$ WH, MBG, 23 Jan. 1849, A1/35.

${ }^{32}$ SGH, MBG (1842-46), 28 Dec. 1842.

${ }^{33}$ University College Hospital Archive

(hereafter UCH), Minutes of General Committee, 12 Mar. and 8 Oct. 1845, A1/2/1.
}

\footnotetext{
${ }^{34} \mathrm{WH}, \mathrm{MBG}, 10$ May 1826, A1/27.

${ }^{35}$ David Thomson, England in the nineteenth century, 1815-1914, London, Penguin, 1991, pp. 63-7.
} 


\section{Early Nursing Reform in Nineteenth-Century London}

night porter and kicked the under-porter so viciously that they broke both bones in his leg. It took seven policemen an hour to restore order and the patients and nurses were all greatly alarmed. ${ }^{36}$

What the governors at the Westminster called the "lack of system and regularity" was not restricted to hospitals. Members of the hospital community were only behaving as many others did. Failure to come to work on a regular basis and to actually do the work once they were in the workplace, horrible problems with drinking, violent tempers, disorder and riots and a high rate of turnover were standard failings throughout the earlier nineteenth century workforce. ${ }^{37}$ Much of early Victorian social policy can be interpreted as an effort to contain and master the unrestrained passions and crude instincts which Victorians thought characterized the lower classes. The upper classes considered it essential to build the popular character. ${ }^{38}$ Character elevation or teaching the workers to be respectable, as the Victorians would have put it, was a standard management strategy throughout the workforce as a whole. It was to become a key element in nurses' training.

\section{The Escalating Need for Better Discipline, Clinical Experience and Improved Working Conditions}

The introduction of anaesthesia in 1846 led to an increase in the number and sophistication of operations and intensified the need for better surgical nursing while at the same time, as the new supportive treatments took hold, medical nursing became more labour-intensive. While there was little improvement in the general level of nursing, hospitals were forced once again to recognize the increasing workload of the nurses. The Westminster began giving their nurses a little paid time off ${ }^{39}$ and the matron started hiring extra, casual nurses when the wards were particularly busy. ${ }^{40}$

In the first part of the century, the primary nursing problem had been getting the nurses to actually stay in their wards and to follow the doctors' orders for patient care. As the century progressed, the need for clinical expertise became just as important. The growing complexity of nursing care meant that some kind of training or at least prior nursing experience was becoming essential. ${ }^{41}$ The doctors at $\mathrm{St}$ George's had indicated this in 1839; in 1847 the doctors at the Middlesex Hospital were even more emphatic. They felt that many of their nurses were deficient in what they termed "nursing knowledge" as well as guilty of insobriety. A spirit of disorder reigned in the hospital and the nurses were generally incompetent and inefficient. Of the thirty-one nurses then on the staff, fifteen had been there no more than six months and seven no more than three months. Such inexperience posed imminent

\footnotetext{
${ }^{36}$ WH, MBG, 27 Dec. 1864, A1/41.

${ }^{37}$ Richard Price, Labour in British society, Dover, Croom Helm, 1986, pp. 34-9, 42-3, 109-10.

${ }^{38}$ Martin J Wiener, Reconstructing the criminal: English culture, law and policy 1830-1914, Cambridge University Press, 1990, pp. $16-18,26-7,32-8,45$.
}

\author{
${ }^{39}$ WH, MBG, 30 Oct. 1849, A1/35. \\ ${ }^{40}$ WH, MBG, 4 Sept. 1849, A1/35; 29 Nov. \\ 1853, A1/37; 29 June 1858, A1/38. \\ ${ }^{41}$ WH, MBG, 21 Dec. 1841, 4 July 1843, A1/ \\ 33; 27 Jan. 1846, A1/34.
}




\section{Carol Helmstadter}

danger to the patients. Furthermore, the nurses were overworked: the night nurses had only six hours a day for sleeping and recreation-the doctors thought they should have more time off and more comforts. As at the Westminster, the Middlesex introduced the sister system hoping it would alleviate their nursing problems. ${ }^{42}$

King's College Hospital, which opened in 1840, had originally used the system of sisters and assistant nurses but, due to a financial crisis in 1843, it discharged the sisters in order to save money. At that time the medical officers asked that charwomen then be hired to scrub the floors, but this request was denied. ${ }^{43}$ In May $1851 \mathrm{Dr}$ Lionel Beale, who had just finished his stint as Physician's Assistant, asked again for cleaning women. The nurses worked a fifteen-hour day, hardly ever getting a chance to sit down, and their health suffered from having to do all the cleaning as well as caring for the patients. During the short time Beale had been in the hospital five of the staff of eight nurses had been off sick from overwork. Each nurse had to scrub down the centre of her ward every morning, and twice a week she had to scour the whole ward, moving every bed. Worse still, during the three hours the scouring took, she was unable to look after her patients. Beale was particularly concerned by the extra night nurses who were hired to look after critical cases. Many had worked all day as charwomen and were simply physically unable to give the patient the unremitting attention required. As a result, patients died unnecessarily from a lack of proper nursing care. Beale suggested hiring cleaners to assist the day nurses and giving the extra night nurses a little more pay and a little beer so that they would not drink the patients' stimulants. The governors hired four charwomen and raised the pay of the night nurses. ${ }^{44}$

At University College Hospital the matron was also meeting the need for additional nurses by hiring the type of untrained casual nurse whom Beale so deprecated. In 1851, Joseph Lister, then a medical student, secured a donation of $£ 50$ from Samuel Gurney, the Quaker philanthropist, to be applied towards paying an additional regular night nurse in the men's accident wards. Gurney subsequently donated another $£ 50$ for a second night nurse. ${ }^{45}$ Lister himself donated $£ 50$ in 1852 and in 1853, Lister, now a Physician's Assistant, told the Board that Gurney would donate $£ 50$ a year for the next two years if the hospital would provide a regular day and a regular night nurse in every ward. The hospital accepted the proposal. ${ }^{46}$ The Westminster was experiencing difficulties with its night nursing as well. In January 1853 , a committee consisting of all the physicians and surgeons of the hospital, plus four lay Board members, abolished the separate night nursing team: the assistant nurses and the night nurses would alternate working both shifts. ${ }^{47}$

\footnotetext{
${ }^{42}$ Middlesex Hospital Archive (hereafter MH), MBG (1845-47), 17 Mar., 28 Apr. and 24 Aug. 1847.

${ }^{43}$ King's College Hospital Archive (hereafter $\mathrm{KH}$ ), Committee of Management, 9 May 1843, $\mathrm{CM} / \mathrm{M} 2$.

${ }^{44}$ Lionel S Beale, Hospitals, patients, doctors and nurses; a lecture, London, J A Churchill,
}

1874, p. 19; KH, Minutes of Committee of Management, 23 May 1851, CM/M4.

${ }^{45} \mathrm{UCH}$, Minutes of General Committee 1844-57, 9 Apr. and 21 May 1851.

${ }^{46}$ Ibid., 7 July 1852,3 Aug. and 16 Nov. 1853.

${ }^{47}$ WH, MBG, 4 Jan. and 1 Feb. 1853 , 


\section{Early Nursing Reform in Nineteenth-Century London}

\section{The Impact of Sisterhood Nursing}

In February 1855, King's College Hospital was preparing to move into its new, larger building and needed to expand its staff of porters and nurses accordingly. $\mathrm{Dr}$ Robert Bentley Todd, the Professor of Physiology and General and Morbid Anatomy, instructed the Secretary to contact St John's House, an Anglican nursing sisterhood, and ask under what conditions the sisters would be prepared to undertake the hospital's nursing. ${ }^{48}$ In 1837, Todd had published a brilliant series of articles on medical education in the British Magazine. ${ }^{49} \mathrm{He}$ felt that medical education in London was lacking, first, in moral restraint and guidance, and second, in the amount of professional instruction which the student received. He thought the medical schools themselves would gradually have to reform medical education by placing the students under the tutelage of respectable senior doctors who would train them in "habits of regularity and order", while they were attaining a practical acquaintance with the first rudiments of professional knowledge. ${ }^{50}$ Todd was soon to be applying these principles at King's.

In the later 1840s, he turned his attention to the lack of nursing education. Together with a group of Broad Churchmen, largely doctors and clergy, Todd designed a training school for nurses based on the same two principles of moral guidance by older, more educated persons, combined with practical, clinical experience. The Training Institution, also known as St John's House, was established in 1848 and run by ladies who were lay Anglican sisters and who were trained nurses themselves. The sisters paid the working-class nurses whom they trained and who worked for the organization, but the ladies donated their work as an act of religious philanthropy. ${ }^{51}$

Anne Summers has written that nursing history in this period can be seen as a sub-plot in the history of Victorian Christianity, ${ }^{52}$ and certainly St John's House completely supports this analysis. Todd worked closely with the clergy in designing the training institution. It was created in part as "a channel for the outpourings of the sympathies of the rich towards the poor", ${ }^{53}$ as Christopher Wordsworth, one of the founders and later the Bishop of Lincoln, expressed it. The first aim of the training school was to elevate the character of the nurses, giving them the prospect of a better social position. ${ }^{54}$ It has been erroneously suggested that it was the philanthropists who characterized the old nurses as Sarah Gamps in order to justify their aspirations for a more autonomous role for nursing in the administrative

\footnotetext{
${ }^{48} \mathrm{KH}$, Minutes of Committee of Management, 16 Feb. and 9 Mar. 1855, CM/M4.

${ }^{49} \mathrm{R}$ B Todd, 'Education of medical students', British Magazine, 1837, 11: 335-8, 460-3, 12: 95-100, 337-41.

${ }^{50}$ Ibid., 12: 95-100, on p. 96.

${ }^{51}$ STH, 'Training institution for nurses for hospitals, families and the sick poor', c.1848, SJ/ A17/1.
}

\footnotetext{
${ }^{52}$ Anne Summers, 'The costs and benefits of caring: nursing charities c. 1830-c.1860', J Barry and $\mathrm{C}$ Jones (eds), Medicine and charity before the welfare state, London, Routledge, 1991 and 1995, pp. $133-48$, on p. 134.

${ }^{53}$ Archives of the Community of the Sisters of St John the Divine, Birmingham, Minutes of Public Meeting held at Hanover Square, 13 July 1848, pp. 13-14.

${ }^{54}$ Ibid., pp. 1-6, 13-14, 18-19.
} 


\section{Carol Helmstadter}

structure of the hospital. ${ }^{55}$ St John's House did indeed lay claim to autonomous status, but while the sisters sought hard-working, reliable and sober women for their nurses, they were not unsympathetic to those hospital nurses who lacked these qualities. "We have left the poor Hospital nurse the victim of a vicious system-and then condemn and shrink from her as degraded", Sister Mary Jones, the third Lady Superintendent of St John's House wrote in $1863 .{ }^{56}$ Jones was to become one of Nightingale's dearest friends and her chief mentor when she was setting up her school at St Thomas's in the early $1860 \mathrm{~s}^{57}$ Although they brought a skeleton staff of their own trained nurses with them when they took over a hospital, St John's House always invited those nurses who were already on staff to remain. ${ }^{58}$

St John's House nurses did only nursing and no cleaning work and they did not live in the miserable quarters which hospitals provided but in an elegant home first in Fitzroy Square, then in what is now Queen Anne's Gate, and later in Norfolk Street. The sisters' nursing also differed from standard hospital nursing systems in that the sisters did not have a separate team of night nurses but used the same nurses at night as in the daytime. The goal of the new training institution was to provide professional nursing services for the poor, for private families, and for hospitals. ${ }^{59}$ Robert Few, a solicitor and one of the early members of the St John's House board, said that Todd had always planned to have St John's House eventually take over the nursing at King's College Hospital. ${ }^{60}$

The advantages of character building, clinical training and better living and working conditions were dramatically illustrated when, in the spring of $1853, \mathrm{St}$ John's House began sending some of its probationers to the Westminster for clinical experience. ${ }^{61}$ During the cholera epidemic of 1854 , the Westminster was unable to

\footnotetext{
${ }^{55}$ Katherine Williams, 'From Sarah Gamp to Florence Nightingale: a critical study of hospital nursing systems from 1840 to 1892', in Celia Davies (ed.), Rewriting nursing history, Totowa, NJ, Croom Helm, 1980, pp. 41-75, on pp. 57-8. Williams bases her argument on two articles written in 1897. In the 1890s a small group of lady nurses, one of whom wrote one of these two articles, had seized control of the nursing leadership and were indeed trying to dissociate themselves from the old working-class nurses. These second generation lady nurses were anything but philanthropists. They were pushing for state registration for nursing in part as a strategy to run the working-class nurses out of business. (See Carol Helmstadter, 'Doctors and nurses in the London teaching hospitals: class, gender, religion and professional expertise 1850-1890', Nursing Hist. Rev., 1997, 5: 161-97, on pp. 181-2.) Florence Nightingale opposed state registration on precisely these grounds - that many of the older, clinically experienced workingclass nurses would not be able to meet the requirements laid down for state registration. (See, for example, British Library (hereafter BL) Miss Pringle to Mrs Fenwick, 6 Mar. 1888, Add.
}

MSs 47735, fol. 81; Nightingale's notes, [1889], Add. MSs 47736, fol. 5.)

${ }^{56}$ Mary Jones to Florence Nightingale, 16 June 1863, BL Add. Mss 47743, fols 202-206.

${ }^{57}$ Sir Edward Cook, The life of Florence Nightingale, 2 vols, London, Macmillan, 1913, vol. 1 , pp. $159,462-4,502$; BL Add. MSs 47743, Jones to Nightingale, 28 Mar. 1860, fols 3-6; ibid., 10 May 1860, fols 11-13; ibid., 11 May 1860, fol. 14; ibid., 27 Aug. 1860, fols 26-27; ibid., 16 Oct. 1860 , fols 35-36.

${ }^{58} \mathrm{KH}$, Minutes of Committee of Management, 25 July 1856, CM/M5; CCH, MBG, 14 Mar. 1865. This was not true of the All Saints Sisters who dismissed all the old nursing staff at University College Hospital when they took over in 1862. (UCH, Minutes of General Committee 1857-66, 23 Apr. 1862, A1/2/2.)

${ }^{59}$ Carol Helmstadter, 'Robert Bentley Todd, St. John's House, and the origins of the modern trained nurse', Bull. Hist. Med., 1993, 67:

282-319, on pp. 299-300, 304-5.

${ }^{60} \mathrm{STH}, \mathrm{R}$ Few, A history of St. John's House, London, 1884, pp. 5-7, SJ/A39/30.

${ }^{61} \mathrm{WH}, \mathrm{MBG}, 12$ Apr., 3 and 10 May 1853, 
staff its cholera ward. St John's House supplied very efficient, trained nurses around the clock. ${ }^{62}$ The medical officers were so impressed that in 1855 a delegation headed by Mr George James Guthrie, perhaps the Westminster's most distinguished surgeon, asked the sisterhood to take over the nursing at the Westminster. ${ }^{63}$ But St John's House was then preparing to provide the nursing at King's College Hospital ${ }^{64}$ and, unfortunately, did not have the staff to take on a second hospital. In the same year, 1855, Dr Henry Bence Jones, a St George's Hospital physician and a leading London practitioner, asked Nightingale to help him organize a training school, but Nightingale was in Scutari and had other matters on her mind. ${ }^{65}$

St John's House was to be enormously successful at King's College Hospital, where they began nursing in March 1856. Other hospitals began adopting some of the Sisters' principles, particularly those which were less costly. At King's College Hospital the nurses had their own bathrooms, sitting room, and a dining room where they were served their meals. Each sister had a bedroom to herself while the nurses slept in dormitories divided into cubicles by wooden partitions with a curtain at the end ${ }^{66}$ These living arrangements were far superior to those of any other hospital at the time. At Guy's, Dr Steele, the professional administrator and a medical doctor, introduced charwomen in April 1857, and in August introduced full board for the nurses. However, he lowered the nurses' wages and reduced the number of nurses to offset the cost. ${ }^{67}$ In 1857, St Thomas's made efforts to remove some of the cleaning duties from the nurses and to provide full bed and board for them. ${ }^{68}$

In 1860, the All Saints Sisters signed a contract to undertake the nursing in Wards 5 and 6 at University College Hospital. ${ }^{69}$ The Sisters used the St John's House system, and it soon became obvious that, although the nursing was very superior, it was more expensive. ${ }^{70}$ Nevertheless, in 1862 a committee, after consulting with Mr Quain and Mr Erichsen, two senior surgeons, Dr Garrod, a senior physician, and the medical officers of Wards 5 and 6, recommended that the sisterhood take on the whole of the nursing. The contract was finalized in April 1862. ${ }^{71}$

The Royal Free Hospital was to make a similar type of arrangement in 1870 . Following what the Victorians called an irregularity between Mr Jeaffreson, the House Surgeon, and Nurse Gilbey for which they both had to leave the hospital, the Royal Free made the Senior House Surgeon responsible for the general efficiency of the wards and the conduct of the nurses. He was to report weekly, while the honorary medical officers were to advise the Weekly Board on all matters connected

\footnotetext{
${ }^{62}$ STH, Lady Superintendent's Diary, 17 Aug. through 14 Sept. 1854, SJ/A20/3; WH, MBG, 22 Aug. 1854, A1/37.

${ }^{63}$ STH, Lady Superintendent's Diary, 15 Dec. 1855, SJ/A20/3.

${ }_{64}$ Ibid., 29 Mar. 1855, 31 Mar. 1856, SJ/A20/3.

${ }^{65}$ Baly, Nightingale and the nursing legacy, op. cit., note 8 above, pp. 8-9.

${ }^{66}$ Lancet, 1864, ii: 298-9.

${ }^{67}$ H C Cameron, Mr. Guy's Hospital 1726-1948, London, Longmans, Green, 1954, p. 346; GY, Officers' Reports 1853-57, 5 Aug. 1857, A67/1.
}

\footnotetext{
${ }^{68}$ Lucy Ridgely Seymer, Florence Nightingale's nurses: the Nightingale Training School, 1860-1960, London, Pitman Medical Publishing Co., 1960, pp. 25-6.

${ }^{69} \mathrm{UCH}$, Minutes of General Committee, 24 Oct. 1860, A1/2/2.

${ }^{70}$ Ibid., 15 Jan., 13 Feb., 24 Apr., 17 and 31 July $1861, \mathrm{~A} 1 / 2 / 2$.

${ }^{71}$ Ibid., 29 Jan., 26 Mar., 9 and 23 Apr. 1862, A1/2/2.
} 


\section{Carol Helmstadter}

with patient care. ${ }^{72}$ The British Nursing Association had been sending some of their probationers to train at the Royal Free since March 1868. This association was a training school established by a group of philanthropists in 1867. It was not associated with one hospital but sent its probationers to a number of different hospitals. ${ }^{73}$ In July 1869, Dr Rickards and the medical staff suggested that the hospital establish a training school for nurses. ${ }^{74}$ Within the year the hospital began negotiations with the British Nursing Association to take over the nursing, and a contract setting up the training school was signed in March $1870 .^{75}$

\section{The Increasing Shortage of Experienced Nurses and the Problem of Accommodation}

Despite the changes in the night nursing system, the nursing at the Westminster remained unsatisfactory, and in May 1861 another nursing committee, consisting of Dr Basham, Mr Holt, a surgeon, and Lord Charles Russell, was struck to report on the nursing as a whole in the hospital. They looked at the nursing arrangements at St George's, St Mary's and King's College Hospitals, and decided to follow their system of hiring charwomen to relieve the assistant nurses of some of their cleaning duties. They hoped this would attract a better class of women. ${ }^{76}$ Only two months after the report of the 1861 committee, in January 1862, the medical officers pressured the Board into appointing a new committee to improve the nursing. ${ }^{77}$ This new committee appreciated the restricted finances of the hospital but believed it was a false economy if the patients were not treated carefully and kindly. The doctors planned on taking a more active role in hiring the nurses. Miss Eager, the Matron, was only to screen candidates and the medical officers would make the final selection. In addition, Miss Eager was to be present at 10 p.m., when the night nurses came on duty, to call the roll and be sure they all showed up.

The committee had personally inspected the sleeping rooms of the matron, sisters and nurses and were struck by the meanness and poverty of the sisters' rooms, which they thought must make this most important office distasteful to many. They strongly recommended improving the accommodation for the nursing staff and matron so that not more than two sisters would have to share the same room. The rooms should be better ventilated and more comfortably furnished. The assistant nurses also needed more comfortable sleeping arrangements and better washing facilities. Finally, they suggested that the matron, sisters and nurses should have their own water closet at the top of the stairs. ${ }^{78}$ The nurses' living quarters at the Westminster were not unusual. In 1858, at St George's, which was a better funded hospital, eight nurses slept in two rooms which had neither fireplaces nor windows. Only one head

\footnotetext{
${ }^{72}$ Royal Free Hospital Archive (hereafter RFH), Minutes of Weekly Board, 2, 16 and 30 July 1868 .

${ }^{73}$ BL, A J Lawrence to Florence Nightingale, 9 June 1868, Add. MSs 45801, fols 63-67.

${ }^{74} \mathrm{RFH}$, Minutes of Weekly Board, 26 Mar. 1868, 8 July 1869.
}

\footnotetext{
${ }^{75}$ Ibid., 3 Feb. and 10 Mar. 1870.

${ }^{76} \mathrm{WH}, \mathrm{MBG}, 14$ May and 12 Nov. 1861, A1/ 39.

${ }^{77}$ WH, MBG, 28 Jan. 1862, A1/40.

${ }^{78}$ WH, MBG, 25 Feb. and 4 Mar. 1862, Al/ 40.
} 


\section{Early Nursing Reform in Nineteenth-Century London}

nurse had a room to herself. Thirteen of the twenty-one rooms used for the nurses' dormitories had no working fireplace and in no instance did any of the nurses have the 1000 cubic feet which was thought to be the healthy allowance of air. ${ }^{79}$

By the 1860s the shortage of reliable, experienced nurses was becoming acute in all the teaching hospitals. Mrs Nelson, the matron at the London Hospital, wrote in January 1862 that she had been in the greatest distress and anxiety for many weeks because she could not recruit enough nurses. She had, she said, a certain number of respectable women on her books whom she could hire as extra nurses when they were required, but when she needed a larger number, they were absolutely not to be found. ${ }^{80}$ The shortage of qualified nurses as well as the doctors' anxieties over the care their patients were receiving was forcing hospitals to improve the nurses' working conditions.

In 1863, the Westminster appointed yet another committee to improve the nursing. This committee reported that all the metropolitan hospitals were improving their nursing and the key to attracting a superior class of nurses was to provide better accommodation. Highly qualified nurses did not apply to the Westminster in 1863 , and among those who did come many did not stay long. The average length of stay for the assistant nurses was six months and eighteen days, while among the sisters, who were somewhat better cared for, there was one who had been in the hospital fourteen years, another twelve and another almost five. ${ }^{81}$ The hospital, which had been built to accommodate eight nurses, now housed a permanent nursing staff of twenty-one, ${ }^{82}$ and there was simply not enough room for them.

However, inadequate space in hospital buildings created a major obstacle to improving the nurses' sleeping quarters. In 1847-48, the Middlesex Hospital, under pressure from the medical staff, improved its nurses' sleeping arrangements, hired charwomen and upped the nurse-patient ratio. As well, the Medical Committee began supervising and instructing the nurses. These measures resulted in better patient care, but the nursing still remained far from meeting the wishes of the Middlesex Board. However, the board pointed out, they had done the most they could until "the present imperfect accommodation" for the nurses could be improved. ${ }^{83}$

The governors at Charing Cross Hospital reached the same conclusion in January 1863. St Thomas's, King's College and University College Hospitals had a much higher class of sisters and nurses with great benefit to the patients but, much as the governors wished to improve the nursing, the hospital did not have adequate space to adopt their system. They suggested buying some houses adjoining the hospital to use as a nurses' home. ${ }^{84}$ In February 1863, Charing Cross established a Medical Committee to deal with the medical affairs of the hospital. By the end of the year, the Committee had decided that the Resident Medical Officer should report at every meeting on the condition of the wards and the conduct of the sisters and nurses.

${ }^{79}$ SGH, MBG 1856-59, 1 Dec. 1858.

${ }^{80} \mathrm{LH}$, Reports of House Committee (1857-65), 5 Mar. 1862, A4/12.

${ }^{81} \mathrm{WH}, \mathrm{MBG}, 30$ June 1863, A1/40.

${ }^{82}$ PP, op. cit., note 3 above, p. 595.

\footnotetext{
${ }^{83} \mathrm{MH}, \mathrm{MBG}$ (1847-49), 18 and 25 Jan, 3 Feb. 1848.

${ }^{84} \mathrm{CCH}, \mathrm{MBG}$ (1856-65), Report of House

Committee, 7 Jan. 1863.
} 


\section{Carol Helmstadter}

The reports detailed the unhappiness of the doctors with the nursing staff. ${ }^{85}$ Within two years, in 1865, Charing Cross began negotiations with St John's House to take over the nursing. The contract was agreed on in $1866 .{ }^{86}$

In the same year, 1866, St George's, under the leadership of Charles Hawkins, a surgeon, made an abortive effort to introduce sisterhood nursing. All the senior surgeons and physicians sat on the committee which recommended that the sisters of St Peter's House take over the nursing. The hospital's open board voted the proposal down because of fears of the High Church practices of the sisters. ${ }^{87}$ In 1866, the Middlesex also made an unsuccessful effort to negotiate a contract with St Luke's Home, Louisa Twining's training school for sisters. Mr Hulke, a surgeon, and Dr Goodfellow drew up the plan for this initiative. The Medical Committee pointed out that dissatisfaction with the nursing had been felt for a long time, "not only by the Medical Officers but, it is believed by very many of the Patients, and also by many friends of the Hospital out of doors". Although many governors had originally been opposed to sisterhood nursing, they found that where it had been introduced it was so superior that no one would revert to the old system. ${ }^{88}$ In 1867 there were difficulties with one of the lady probationers and Miss Twining withdrew. After inspecting the nursing at St Thomas's, King's College and University College Hospitals, the hospital established its own training institution in 1867 under the direction of Miss Catherine Martyr, an All Saints trained nurse. ${ }^{89}$

Returning to the Westminster in 1863, the hospital appointed a special subcommittee consisting of two surgeons, $\mathrm{Mr}$ Brooke and $\mathrm{Mr}$ Holthouse, and two physicians, Drs Fincham and Radcliffe, to look into the additions to the nurses' accommodation. ${ }^{90}$ Rather than opening two new wards as had been planned, they decided to spend the money on building a comfortable day room and two additional sleeping rooms for the nurses. The nurses' health was of great concern ${ }^{91}$ for there was a serious outbreak of typhus among the nursing staff in the early 1860s. In July 1862, after consulting with St Mary's, St Bartholomew's, the London, University College, the Middlesex and St George's Hospitals, the Westminster decided to adopt their practice of not making those nurses who were off sick pay their own substitute. ${ }^{92}$ This was to be a somewhat expensive decision for between February 1863 and May $1865,{ }^{93}$ a little over two years, out of a total staff of only twenty-one, three nurses died and at least nine were laid off for significant periods with typhus.

By the summer of 1864, the nurses' new rooms, built on the roof of the hospital,

${ }^{85} \mathrm{CCH}$, Minutes of the Medical Committee, 12 Feb. and 29 Dec. 1863, 26 Jan., 29 Mar., 20 Dec. 1864, 10 Jan., 21 Mar. 1865. 1866.

${ }^{86}$ Ibid., MBG (1865-68), 5 Apr. 1865, 5 Jan.

${ }^{87}$ SGH, MBG 1864-66, 24 Jan., 21 Feb. and 20 Apr. 1866; Br. med. J., 1866, ii: 445. Hawkins was responsible for many of the improvements to the living and working conditions for the nurses. (See, for example, SGH, MBG, 9 and 30 May 1866.)

${ }^{88} \mathrm{BL}$, 'Middlesex Hospital report on the subject of nursing', Dec. 1865, and 'Report of
Weekly Board appointed 6 February 1866', Add. MSs 45752, fols 125-28.

${ }^{89} \mathrm{MH}$, Minutes of Medical Committee, 22 June 1867; MBG, 3 Sept. 1867.

${ }^{90} \mathrm{WH}, \mathrm{MBG}, 5$ May 1863, A1/40.

${ }^{91} \mathrm{WH}, \mathrm{MBG}, 30$ June and 14 July 1863, A1/ 40.

${ }^{92} \mathrm{WH}, \mathrm{MBG}, 1$ July 1862 , A1/40.

${ }^{93} \mathrm{WH}, \mathrm{MBG}, 24 \mathrm{Feb}, 16$ and 23 June, 8 and 15 Dec. 1863; 12 and 26 Jan., 9 Feb., 26 Apr. 1864, A1/40; 31 Jan., 30 May 1865, A1/41. 


\section{Early Nursing Reform in Nineteenth-Century London}

were ready. Each was to accommodate five nurses while no more than four would sleep in the old rooms then in use. ${ }^{94}$ Several months later the Board agreed to give the sisters three weeks and the assistant nurses two weeks holiday during which time the Board paid their substitutes. ${ }^{95}$ In addition to the doctors' concern for the nurses' health and the need to be able to attract skilled nurses, the rising standard of living also forced hospitals to make these expensive improvements. By the 1860 s workingclass women were not only expecting better hours and working conditions but they were no longer willing to accept the wretched accommodation which hospitals had provided in the earlier part of the century. Victorian additions and alterations to their homes typically involved better plumbing arrangements and separate and better accommodation for the servants. This was the age when wealthier people were building servants' wings, providing more privacy with perhaps two to a bedroom in place of six, and often separate male and female staircases. ${ }^{96}$

In 1868, the British Medical Journal published an article on the Westminster which was highly critical of its nursing service. The nursing staff did not wear uniforms and the sisters' dresses were often shabby and torn. The assistant nurses were even more untidy and shabbily dressed, and, in too many cases, ignorant of what real nursing was. Some of the sisters were excellent but others were inferior to the usual class of paid sisters in London. ${ }^{97}$ (The mention of paid sisters was an indirect reference to the unpaid Anglican sisters, whose nursing was considered to be in a different class. ${ }^{98}$ ) There was no training school, and many of those appointed to full duty in the wards knew nothing at all about nursing. The wards were badly understaffed and the nurses had to clean the grates and wash the wards as well as the sculleries, closets, clothes-boxes and lockers. The only other major hospital in London where the assistant nurses had to do as much cleaning was Guy's, but Guy's had a nurse-patient ratio of 1:5.3 while the ratio at the Westminster was 1:7. Even after the improvements made only a few years previously, the Journal found the room and board for the nurses sadly wanting. The sisters slept in dormitories which were less comfortable than the wards, poorly furnished and supplied with only the bare necessities, many of which needed to be repaired or replaced. The ordinary nurses' sleeping quarters were even worse, and their water closets, which were half way up the stairs just below the top floor, had no window or ventilator. ${ }^{99}$

Nursing services at the Westminster in the first two-thirds of the century obviously left much to be desired. But, as the British Medical Journal pointed out, although some of the sisters were inferior, some were excellent. Sarah Boddington is an example of one of the latter. She began working at the hospital as an assistant nurse in November 1860 when she was thirty years old. One year later, in December 1861,

\footnotetext{
${ }^{94}$ WH, MBG, 25 Aug., 10 Nov. 1863, A1/40; 14 June 1864, A1/41.

${ }^{95} \mathrm{WH}, \mathrm{MBG}, 19$ July and 4 Oct. 1864, A1/41.

${ }^{96} \mathrm{~F} \mathrm{M}$ L Thompson, The rise of respectable society: a social history of Victorian Britain 1830-1900, London, Fontana, 1988, pp. 156-7.

97 'Report on the metropolitan hospitals: II. The Westminster Hospital', Br. med. J., 1868, ii: 228-9.
}

\footnotetext{
${ }^{98}$ The St John's House sisters, their assistant or ordinary nurses and the probationers all wore uniforms which were the prototype of the traditional nursing uniform. The All Saints sisters, who nursed at University College Hospital, wore nuns' habits but their nurses and probationers wore standard nursing uniforms.

99 'The Westminster Hospital', Br. med. J., 1868, ii: 228-9.
} 


\section{Carol Helmstadter}

she was appointed Head Nurse in the women's surgical and obstetrical wards. She remained six years until November 1867 when she left to become matron of the Brighton Workhouse Infirmary. The House Committee commended her for "the very efficient and kind manner in which she has performed her duties to the patients". 100

From the beginning of the century there were always a number of competent and kind nurses. In 1827 the Westminster Board gave Ann Stuart a gratuity of a guinea and a half although she had been on staff for only nine months and the custom was to give these gifts only after a full year. An exception was made in Stuart's case because she gave such industrious care to her patients and had such an excellent character. ${ }^{101}$ Mary Ann Noble, an assistant nurse at the Westminster who went to Scutari with Mary Stanley's party in 1854, was described by Florence Nightingale as "an invaluable person". Nightingale paid her the top salary of 18s. a week (as opposed to the bottom wage of $10 \mathrm{~s}$.). ${ }^{102}$ Noble was an experienced nurse, having previously worked at the London Hospital. She was invalided home after seven months in the East ${ }^{103}$ and was made a head nurse at the Westminster on 1 January 1856. ${ }^{104}$ In 1855, Mary Tattersall, who had received a few weeks' training at the Westminster before going to Scutari, sent the hospital a donation of $£ 5$, the first money she had ever earned, in thanks for the kindness she received in the wards while she was learning there. ${ }^{105}$

At the same time, the fact that kindness was always commented on and specially rewarded suggests that it was the exception, not the rule. This was the view of $\mathrm{Mr}$ Joseph Bell, an Edinburgh surgeon, who had been practising since the 1840s. The pre-reform nurses tended to have bad tempers or no character or were lazy. "Some of these", he explained, "found their vocation, and by a sort of natural turn for it, became valuable nurses." But their value was frequently compromised by drinking bouts or by coarseness of voice and speech. "Exceptions there were", he wrote in 1876, "whose supreme excellence and capacity cannot be overestimated, and for whose sake it is difficult for us older men to hear a word against the old system". ${ }^{106}$

One wonders how, given the generally unsatisfactory state of the nursing and the doctors' extreme unhappiness with it, the Westminster could have been used as a training ground for St John's House as well as for other organizations and individuals. The fact was that for all the failings of the old hospital nurses, a good many of them knew more about nursing than anyone else except the doctors. The teaching hospitals were the only place where women could learn the requirements of up-todate nursing care, for, by mid-century, familiarity with the new medical therapeutics had become a key part of what the doctors at the Middlesex called nursing knowledge.

Mrs Fry recognized this when she founded her Protestant Sisters of Charity in

\footnotetext{
${ }^{100} \mathrm{WH}$, Register of Servants of the Westminster Hospital, no pagination, A40/3; MBG 13 Aug. 1867, A1/42.

${ }^{101}$ WH, MBG, 17 Oct. 1827, A1/28.

${ }^{102}$ STH, 'Nurses sent to military hospitals in the east', p. $11, \mathrm{NC} 8 / 1$.

${ }^{103} \mathrm{STH}$, 'List of nurses and sisters who left', p. $2, \mathrm{NC} 8 / 4$.
}

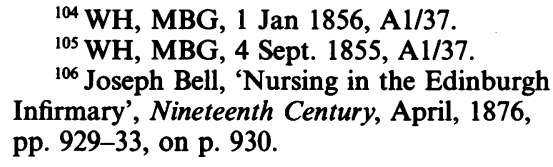




\section{Early Nursing Reform in Nineteenth-Century London}

1840 (the name was soon changed to the "Institution of Nursing Sisters"). These nurses did largely domiciliary nursing but, because they had to be familiar with modern medical practice if they were to be what the Victorians called "efficient nurses", they spent short stints working in a teaching hospital before going out to look after patients. ${ }^{107}$ During the Crimean War such experience was considered essential. ${ }^{108}$ Jane Shaw Stewart spent approximately a month in the fall of 1854 attending in the wards of the Westminster "learning the business of a nurse", before leaving for the East with Mary Stanley's party. ${ }^{109}$ Among many other individual ladies, Catherine Wood, later Lady Superintendent of the Hospital for Sick Children in Great Ormond Street, attended for three months in $1864 .{ }^{110}$ The Anglican Sisters at East Grinstead sent sisters on a regular basis, ${ }^{111}$ the British Nursing Association trained some of its probationers in the Westminster's wards, ${ }^{112}$ and Mrs Ranyard also sent some of her Bible nurses there. ${ }^{113}$

\section{The Introduction of Training at the Westminster}

The hospital set up yet another committee to improve the nursing in response to the adverse publicity in the British Medical Journal. ${ }^{114}$ It was to be the first of five such committees in the next three years. The most important recommendation which the various committees made was that the old matron, Miss Eager, should be replaced by a Superintendent of Nursing who, like the Anglican nursing sisters, was to be a trained nurse herself. Her chief duty would be to see that the nurses actually did their work. An upper servant would take over Miss Eager's responsibilities for the bedding, linen, dressings, and supervision of the kitchen and cleaning staff. The nurses were to wear a uniform consisting of a white cap and apron to distinguish them from the patients. ${ }^{115}$

Miss Charlotte Spencer was elected matron in July 1871 but died of fever in the hospital a few months later. ${ }^{116}$ In February 1872 she was replaced by Mrs Maria Eliza Barber, previously matron at the Kent and Canterbury Hospital. ${ }^{117} \mathrm{Mrs}$ Barber was a St Thomas's trained nurse but she had had a chequered career with the Nightingale Fund. Mrs Wardroper recommended dismissing her, and in 1868 she resigned from the Fund. ${ }^{118}$ During Mrs Barber's brief matronship in 1872-73 the hospital shortened the nurses' working hours and provided the nurses with their own dining room where they were served their meals so they no longer had to cook

\footnotetext{
${ }^{107}$ Geoffrey Rivett, The development of the London Hospital system 1823-1982, London, King Edward's Hospital Fund for London, 1986, pp. 36-8.

${ }^{108}$ Fanny Taylor, Eastern hospitals and English nurses: the narrative of twelve months experience in the hospitals of Koulali and Scutari, London, Hurst \& Blackett, 1856, vol. 1, pp. 9-10. 37.

${ }^{109} \mathrm{WH}, \mathrm{MBG}, 24$ Oct. and 5 Dec. 1854, A1/

${ }^{110}$ WH, MBG, 23 Aug. 1864, A1/41.

${ }^{11}$ See, for example, WH, MBG, 26 Apr. 1859, A1/39; MBG, 13 Feb. 1872, A1/44.
}

${ }^{112} \mathrm{WH}, \mathrm{MBG}, 4$ Feb. 1868, Al/42.

${ }^{113}$ WH, MBG, 21 Jan. 1868, A1/42.

${ }^{114}$ WH, MBG, 1 Sept., 15 Dec. 1868, A1/42.

${ }^{115} \mathrm{WH}, \mathrm{MBG}, 19$ and 26 Oct. 1869, 14 Feb. 1870, Al/43; 31 May and 21 June 1870, Al/43.

${ }^{116} \mathrm{WH}, \mathrm{MBG}, 18 \mathrm{July}, 5$ and 27 Dec. 1871, A1/44.

${ }^{117}$ WH, MBG, 27 Dec. 1871, 30 Jan. 1872 , A1/44.

${ }^{118}$ STH, Mrs Wardroper to Bonham-Carter, 27 and 29 Nov. 1866, NC18/7/30 and 32; Baly, Nightingale and the nursing legacy, op. cit., note 8 above, p. 241. 


\section{Carol Helmstadter}

over the ward fire. Better furniture was provided for the nurses' rooms and one room was even fitted up with a bath tub. Another room on the roof for the nurses was planned, more charwomen were hired and the nurses were finally relieved of all their menial duties such as scrubbing floors and cleaning coal grates. ${ }^{119}$ The medical officers were supported in making these expensive improvements by a strong ladies' committee chaired by Lady Augusta Stanley who was prepared to pay for many of the enhancements. ${ }^{120}$

Eight months after Mrs Barber arrived, on 2 November 1872, Mary Ann Richards, a newly hired 36-year-old assistant nurse, was fired for drunkenness, neglect of her patients, being impertinent to the House Physician and refusing to return to her ward. ${ }^{121}$ Her misdemeanours triggered a strong reaction among the medical officers who, the following week, pronounced the nursing unacceptable. Rather than improving, the doctors said, the nursing had been deteriorating since Mrs Barber came. There was no systematic communication between assistant and head nurses and between head nurses and the matron, who really did not know what was going on in the hospital-precisely the same problem as in 1838. Nor did the matron consider it part of her duties to instruct the assistant nurses. The nursing service was understaffed and underpaid so it did not attract skilled nurses. On the urgent request of several of the doctors a new nursing committee consisting entirely of medical staff was appointed on 12 November. This committee in turn appointed a sub-committee to look at the nursing arrangements elsewhere, particularly in King's College, Charing Cross and University College Hospitals, ${ }^{122}$ the three metropolitan hospitals nursed by Anglican sisters. The fact that the medical staff considered Nurse Richards' behaviour insupportable, when but a few years previously it would have warranted only a reprimand, is an indication of how far the reformation of manners had progressed by 1872 .

The new committee was chaired by Sir Rutherford Alcock who was a surgeon but no longer practising, ${ }^{123}$ and included Dr Basham who was always an outspoken advocate of the nurses. After surveying ten other hospitals, the committee was completely convinced that no matter how skilful the medical officers were, nor how much money the hospital spent on its patients, it would be ineffective if the nursing was bad. Good nurses required previous and intelligent training under superior guidance. Four factors-low wages, understaffing, poor room and board, and the cleaning and scrubbing which the Westminster's assistant nurses had to do-were fatal to good nursing. These were, of course, the areas which the Anglican sisters had so dramatically improved. Of these four factors, superior and qualified women found the poor accommodation and eating arrangements, and the cleaning duties more objectionable than overwork or low pay.

\footnotetext{
${ }^{119}$ WH, MBG, 9 Apr. and 7 May 1872, A1/44.

${ }^{120} \mathrm{WH}, \mathrm{MBG}, 13 \mathrm{Feb}$. and 9 Apr. 1872, A144.

${ }^{121}$ WH, MBG, 5 Nov. 1872, A1/44; Register of Servants, no pagination, A40/3.

${ }^{122}$ WH, MBG, 12 Nov. 1872; Report of SubCommittee on Nursing, 21 Jan. 1873, Al/44.

${ }^{123}$ Alcock had been a student and a House

Surgeon at the Westminster and later an army
}

surgeon. In 1844 he went into the diplomatic service from which he retired in 1871. John Langdon-Davies, Westminster Hospital: two centuries of voluntary service 1719-1948, London, John Murray, 1948, p. 11; Dictionary of National Biography, Supplement, vol. 22, Oxford University Press, 1917, pp. 29-30. 


\section{Early Nursing Reform in Nineteenth-Century London}

Alcock's committee found that, generally speaking, there were three systems of nursing. First, there was the old or traditional system with no training school. The Westminster, the London, St Mary's, St Bartholomew's, and St George's to a lesser extent, used this system. However, St George's was now introducing a special nursing superintendent as well as probationers. Second, there was the system of contracting the whole of the nursing out to a sisterhood, as at King's College, University College and Charing Cross, or to a nursing organization such as the British Nursing Association at the Royal Free. Third, there was the very satisfactory system of a lady superintendent in charge of a training institution as at the Middlesex and the Liverpool Royal Infirmary. ${ }^{124}$

Of the twelve teaching hospitals in London, the committee did not survey Guy's and St Thomas's. Guy's was still using the old system. St Thomas's was in a different class because the Nightingale Fund paid for the nurses' home, and Florence Nightingale's publicity was beginning to attract a few superior candidates. The inclusion of one provincial hospital, the Liverpool Royal Infirmary was not haphazard. Miss Elizabeth Merryweather, the Lady Superintendent, had contacted the Westminster in January 1872, shortly after the death of Miss Spencer and before the election of Mrs Barber, expressing interest in the position. ${ }^{125}$

The medical officers in the hospitals where the old system was in force were all very dissatisfied with it. It was by far the least efficient and the most difficult to improve. Although the nurses' wages at the Westminster were somewhat lower and the accommodation somewhat poorer, at hospitals such as St George's and St Bartholomew's, where everything seemed to have been done for the nurses, the system was still unsatisfactory and could not compare with the efficiency of trained nurses under a special nursing superintendent. The second system, that of contracting out the nursing to trained nurses under a lady superintendent who was a trained nurse herself, gave far superior results and was in many respects highly efficient and satisfactory, but it was more expensive and could lead to conflicts of authority as had happened at King's College Hospital where the sisters of St John's House had proved too independent for the taste of the hospital Committee of Management.

Alcock's committee recommended adopting the system used at the Liverpool Royal Infirmary. The training institution sent nurses out to private families and was funded by the profits they brought in, as well as by private subscriptions. The Infirmary had a contract with the training institution, paying it a fixed sum of money to provide its nursing. A committee composed of men who were all members of the Royal Infirmary's House Committee managed the training institution so there could be no conflict of authority between the two bodies. Perhaps even more appealing, the cost of the nursing at the Liverpool Royal Infirmary was by far the lowest in the eleven hospitals surveyed- $£ 5$ per bed as compared with $£ 78 \mathrm{~s}$. $6 \mathrm{~d}$. at the Westminster, £9 12s. 0d. at St George's, £11 16s. 6d. at St Bartholomew's, and $£ 13$ 5s. 0d. at King's College, which was the most expensive. ${ }^{126}$

\footnotetext{
${ }^{124} \mathrm{WH}, \mathrm{MBG}$, Report of Sub-Committee on Nursing, 21 Jan. 1873, A1/44.

${ }^{125}$ WH, MBG, 9 Jan. 1872, A1/44.
} 


\section{Carol Helmstadter}

Miss Merryweather agreed to come as Lady Superintendent bringing with her two or three of her trained nurses, who would form a nucleus until the Westminster's own training institution was functioning. Then the hospital could gradually eliminate its current less efficient nurses and replace them with women trained in its own school. Mrs Barber was given three months' notice plus a year's salary of $£ 80$ in addition to her wages and dismissed. She was, not surprisingly, unhappy. The House Committee explained to her that her dismissal was not intended to suggest that her performance of the ordinary duties of a matron, particularly her superintendence of the house servants and her management of the linen and other stores, was inefficient. ${ }^{127}$ In short, despite her St Thomas's nurses' training, Mrs Barber was an old style housekeeper type of matron. As Monica Baly has pointed out, the training at St Thomas's under Mrs Wardroper was not a break with the past. ${ }^{128}$ Two years later, in 1875, out of a field of thirty-three candidates, Mrs Barber was unanimously elected matron of the Great Northern Hospital. There she remained for ten years, albeit at a lower starting salary, $£ 60$ a year. ${ }^{129}$ As Night Nurse Dewar demonstrates how few clinically experienced hospital nurses were to be found in London in 1847, Mrs Barber is an illustration of the paucity of suitable trained nurses to serve as matrons in the 1870 s.

\section{The Establishment of the Westminster Training School}

Miss Merryweather arrived in the spring of 1873. She found the nurses' dormitories and the corridors leading to them very dirty and overrun with vermin. The nurses could not use their lavatory because a bed for a nurse had been squeezed into it. It was absolutely essential to improve the accommodation and to buy new beds and bedding. ${ }^{130}$ The following year, the hospital was prepared to establish a training institution. As the importance of efficient nursing was increasingly recognized, the demand for trained nurses rapidly surpassed the supply. ${ }^{131}$ Indeed, the situation had become even worse than when Mrs Nelson described the problem at the London in 1862. Miss Swift, Mrs Nelson's successor, pointed out in December 1874 that the difficulties in her department would be greatly alleviated if she could only obtain "well conducted trained nurses". ${ }^{132}$ The following March she reported that she had never had so much difficulty staffing her department, largely owing to so many nurses being on the sick list from overwork. ${ }^{133}$ She simply could not find respectable people to replace them. In 1880, Dr Steele, who had been at Guy's since 1853, explained that the "supply of the raw material for making nurses" had been diminishing rapidly during the last few years. Guy's used to be able to hire experienced

\footnotetext{
${ }^{127}$ WH, MBG, 1 Apr. 1873, A1/44.

${ }^{128}$ Baly, 'The first school at St. Thomas's', op. cit., note 1 above, pp. 18-19.

${ }^{129}$ Eric O Jewesbury, The Royal Northern Hospital: the story of a hundred years' work in north London, London, H K Lewis, 1956, p. 41 .
}

\footnotetext{
${ }^{130} \mathrm{WH}, \mathrm{MBG}, 20$ May 1873, Al/44.

${ }^{131}$ WH, MBG, Report of Nursing SubCommittee, 9 June 1874, A1/45.

${ }^{132}$ LH, Reports of House Committee, 5 Dec. 1874, A4/14.

${ }^{133}$ Ibid., 3 Mar. 1875, A4/14.
} 


\section{Early Nursing Reform in Nineteenth-Century London}

nurses from Bart's, St George's and St Thomas's, he said, but this supply had stopped many years previously. ${ }^{134}$

Alcock felt that a training institution attached to the hospital was the only way to supply an adequate nursing staff. ${ }^{135}$ St Mary's Hospital gave the same reason for establishing a training school in 1880 - to provide an adequate number of nurses for the hospital. ${ }^{136}$ Miss Merryweather was already training probationers in the hospital but she could not attract and keep the best sort of women unless she could provide them with a comfortable home. The nursing committee proposed renting a house in the neighbourhood. This would be an additional cost, but was well worth it because good nursing was one of the most important prerequisites of successful medical treatment. ${ }^{137}$ The Westminster established its home for the probationers at 27 Queen Anne's Gate in 1874 . $^{138}$ They were now comfortably housed but the Sisters and staff nurses' accommodation in the hospital remained cramped and unpleasant. Three years later, in 1877, their living quarters were upgraded when a fourth storey was added to the hospital. The new nurses' rooms were next to the wards for the contagious and delirious patients, but they had the advantage of being approached by a private staircase. ${ }^{139}$

Although she was often advertised as a Nightingale nurse, the extent of Merryweather's training was two months at St Thomas's as an observer in $1862,{ }^{140}$ and a little time the same year with Sister Mary Jones at King's College Hospital. ${ }^{141}$ With her new comfortable nursing home Merryweather was able to establish respectability and better order among the probationers, or what Todd in the 1840s called providing moral guidance and developing habits of regularity and order. Merryweather's job was easier than that of Mrs Cox and Miss Steele because, by the 1870s, the workforce as a whole was better educated, more sober and more habituated to the kind of work discipline which a modern hospital required.

Merryweather could not, however, give the probationers the practical clinical instruction which the rapid advances in medical practice made mandatory. It was not until 1880 when Merryweather died suddenly and was succeeded by Miss Mary Jane Pyne, that the Westminster's school met Todd's second requirement of providing a professional, clinical education. ${ }^{142}$ Pyne was a St Thomas's trained nurse, but more important, she had spent seven years as assistant to A L Pringle, Lady Superintendent of the Edinburgh Royal Infirmary and the most successful matron the Nightingale

${ }^{134}$ GY, General Court, 11 Mar. 1880 , pp. 176-8, A225/2.

${ }^{135}$ WH, MBG, 24 Mar. 1874, Al/45.

${ }^{136}$ Although the hospital was founded as late as 1849 , St Mary's faced the same problem in doing this as the Westminster, a lack of accommodation for the probationers. By 1880 , the hospital was already housing some of its nursing staff outside the hospital building. (St Mary's Archive, 23 July 1880, SM/AD1/15.)

${ }^{137}$ WH, MBG, Report of Nursing SubCommittee, 9 June 1874, A1/45.
${ }^{138} \mathrm{~J}$ G Humble and Peter Hansell, Westminster Hospital 1716-1966, London, Pitman Medical Publishing Co., 1966, p. 83; WH, MBG, Report of Nursing Sub-Committee, 9 June 1874, Al/45.

${ }^{139}$ Humble and Hansell, op. cit., note 138 above, pp. 62, 83.

${ }^{140}$ Baly, Nightingale and the Nursing legacy, op. cit., note 8 above, p. 46.

${ }^{141}$ STH, 'Nursing in a large town', pp. 22, 38, $\mathrm{NC} 7 / 2$.

${ }^{142}$ WH, MBG, 11 May and 5 Oct. 1880, A1/ 47. 


\section{Carol Helmstadter}

school produced. ${ }^{143}$ Pyne was therefore, like the Anglican Sisters, well qualified to give the probationers clinical instruction. To be fair to Merryweather, in 1880 after seven years of her superintendence, Pyne found the Westminster nurses "quiet and orderly" and "a good group of good kind women who love their work and take pride in it". Most seemed to belong to some section of the middle class and Pyne thought there was perhaps a bit too much youth and beauty, but there was a nice tone in the wards. ${ }^{144}$

"Tone" was of great importance in the new professionalizing society and carried more weight than the rather snobbish connotation which it seems to convey on the surface. Hospital governors-lay as well as medical-had always objected to coarseness of speech, uncontrolled tempers and lack of manners, but had frequently been forced to accept such behaviour for lack of better. They recognized, however, that it compromised good patient care and made it difficult to build a loyal and cohesive nursing team. However, while the medical officers appreciated a better tone, competent and experienced sisters were still so rare in the late 1870 s that doctors were prepared to overlook a good deal if the nurse had good clinical skills and could be relied on to carry out their orders.

For example, in December 1879 Merryweather fired Sister Matthew for unnecessarily sending a young nurse on her ward to one of the visiting physicians. Merryweather had given the sister many warnings in the past and found it difficult to keep nurses in her ward because of her irritable temper and her habit of speaking loudly of the nurses' faults in front of the patients. Besides, Merryweather added, Sister Matthew expressed herself in a coarse and ill-bred way when describing the patients and their conditions and had "a very inadequate idea of how objectionable to me and to others this conduct is". Mr Gould, one of the surgeons, objected strenuously to Sister Matthew's discharge on the grounds that she was a highly competent nurse. She was "most attentive to her patients, unsparing of trouble and careful to carry out precisely all the orders she receives", he explained. "Her experience renders her assistance most valuable in all serious cases and in parting with her the Hospital will lose a most efficient servant." The House Committee approved the Lady Superintendent's action but, in view of Sister Matthew's long service, allowed her to resign rather than discharging her. ${ }^{145}$

The last four hospitals to introduce training schools were St Mary's, St Bartholomew's, Guy's and the London. In 1875 St Mary's Hospital, where doctors did sit on the board, asked the Nightingale Fund to help with its nursing. Rachel Williams, one of Nightingale's favourite pupils, was elected matron in 1876. She took with her eight Nightingale nurses, most of whom did not stay. Williams was a rather prickly character and alienated the medical staff, who forced her to resign in 1885. ${ }^{146}$ At the remaining three hospitals, where doctors did not sit on the board,

${ }^{143}$ STH, H Bonham-Carter, unsigned rough draft of letter of recommendation, 2 Aug. 1880, NC18/26/45.

${ }^{144}$ BL, Mary Jane Pyne to Florence Nightingale, 23 Oct. 1880, Add. MSs 47745.

${ }_{145} \mathrm{WH}, \mathrm{MBG}, 23$ and 30 Dec. 1879 ,

\footnotetext{
${ }^{146}$ STH, Mrs Wardroper's Reports 1878 and 1879, NTS/A3/3 and A3/4; Baly, Nightingale and the nursing legacy, op. cit., note 8 above, pp. 164-5.
} Al/46. 


\section{Early Nursing Reform in Nineteenth-Century London}

lay administrators introduced the new nursing. All three had tried unsuccessfully to train nurses under their old, non-nurse matrons, and at Bart's and Guy's, doctors at first resisted the new arrangements. ${ }^{147}$ In January 1879, Maria Machin, a Nightingale nurse, became matron at St Bartholomew's at the behest of Sir Sidney Waterlow, the Treasurer. In November of the same year, Mr Edward Lushington, the Treasurer at Guy's, brought a St John's House trained matron, Margaret Burt, to the hospital, and in 1880, the House Committee at the London appointed Eva Lückes, a Westminster trained nurse, as matron.

\section{Conclusion}

"None, probably but medical men", the Westminster medical staff wrote in 1874, "can guess how many lives are lost by bad and inefficient nursing, or the saving of health which one thoroughly trained Nurse can effect."148 Trained nursing had become a cornerstone of hospital therapeutics. In the earlier part of the century order and cleanliness in the wards were the primary concerns of the lay governors. As the century progressed and clinical nursing knowledge became a primary concern, they lagged behind the medical governors in recognizing the need for more up-todate nursing practice and the importance of professional, clinical instruction. The doctors, however, were acutely aware of this lack and in the hospitals where they were board members, they insisted on significant improvements in the night nursing. They also began pushing through expensive improvements in pay, ${ }^{149}$ accommodation, and working conditions. Without these provisions it was not possible to attract and keep any able working-class women or the quiet orderly women from the middle classes whom Miss Pyne later commented on.

For many years those doctors who were generally dedicated to good patient care had taken pains to teach the sisters of their wards. ${ }^{150}$ By mid-century, however, not only the sisters but the ordinary nurses had to be knowledgeable if the nursing were to be effective. Furthermore, the knowledge required of an ordinary nurse could no longer be picked up by working a few months in the wards with haphazard instruction from the sister. Instructing the nursing staff in his ward had become too big a job for a busy professor of medicine or surgery. As Todd had appreciated in 1848, individual, voluntary efforts were not adequate to produce the large number of reliable, clinically competent nurses which the new therapeutics required. Nursing reform had to be systematically organized and directed by someone from within the profession who could apply herself full time to the job.

\footnotetext{
${ }^{147}$ See St Bartholomew's Hospital Archive, Minutes of Medical Committee 1843-78, 1 Apr. and 24 June 1876, MC1/1; GY, Mr Lushington's Statement, 12 July 1880, A224/3; GY, Printed Reports of General Court, 3, 10-11 Mar. 1880, A 225/1-2.

${ }^{148}$ WH, MBG, Report of Nursing SubCommittee, 9 June 1874, A1/45.

${ }^{149}$ Hospitals increased the nurses' wages steadily from the beginning of the century until
}

the training schools were established. The Westminster paid $£ 8$ a year in 1809; in 1873 assistant nurses made up to $£ 16$ ss. and the Head Nurses up to $£ 26$ 5s. (WH, MBG, 28 June 1809 , A1/24; Report of Sub-Committee on Nursing, 11 Feb. 1873, A1/44.) The nineteenth century was not an inflationary period; rather the value of money remained fairly stable.

${ }^{150}$ For example, see South, op. cit., note 5 above, pp. 15-16. 


\section{Carol Helmstadter}

As the sisterhoods introduced trained nursing, it was the medical men at King's College, University College, Charing Cross and the Royal Free Hospitals, who urged the contracts with St John's House, the All Saints sisters and the British Nursing Association. It was the doctors at St George's who led the push for sisterhood nursing in 1866 and later for their own training school, the doctors at the Middlesex who were responsible for the establishment of the new training institution in 1867, and the doctors at the Westminster who insisted on the new training system in 1873-74.

By 1880 all the teaching hospitals, with the one exception of St Thomas's, had training schools directed by matrons who were trained nurses. In the 1870 s doctors became concerned with their loss of control over the nurses in their wards, and by the 1880 s nursing reform was to take on a different character as many of the new lady nurses focused on gaining state registration while hospitals developed nursing schools which were directly under their own control and not based on contracts with outside groups. In the earlier part of the century, however, it was the medical staffs who pushed the innovative changes in nursing. And it was a doctor who conceptualized the training institution which became the basis for the new trained nurse. 